\title{
Occupational exposure to carcinogens in the European Union
}

Finnish Institute of Occupational Health, Helsinki, Finland

T Kauppinen

J Toikkanen

A Savela

National Institute for Occupational Safety and Health,

Cincinnati, OH, USA

D Pedersen

$\mathrm{R}$ Young

Bremen Institute for Prevention Research and Social Medicine, Bremen, Germany W Ahrens

International Agency for Research on

Cancer, Lyon, France P Boffetta

M Kogevinas

Danish Cancer

Society, Copenhagen, Denmark

J Hansen

Wageningen

University,

Wageningen, The

Netherlands

H Kromhout

Instituto Nacional de Seguridad e Higiene en el trabajo, Madrid, Spain

J Maqueda Blasco

$\mathrm{V}$ de la Orden-Rivera

Agenzia per la Protezione Ambientale del Piemonte, Grugliasco, Italy D Mirabelli

Medical Research Council,

Southampton, UK

B Pannett

Karolinska Hospital, Stockholm, Sweden N Plato

Institut National de Recherche et de Sécurité, Vandoeuvre, France

R Vincent

Institut Municipal d'Investigació Mèdica, Barcelona, Spain M Kogevinas

Correspondence to: Dr T Kauppinen, FIOH, Topeliukenk 41aA, 00250 Helsinki, Finland

Timo Kauppinen, Jouni Toikkanen, David Pedersen, Randy Young, Wolfgang Ahrens, Paolo Boffetta, Johnni Hansen, Hans Kromhout, Jeronimo Maqueda Blasco, Dario Mirabelli, Victoria de la Orden-Rivera, Brian Pannett, Nils Plato, Anja Savela, Raymond Vincent, Manolis Kogevinas

\begin{abstract}
Objectives-To construct a computer assisted information system for the estimation of the numbers of workers exposed to established and suspected human carcinogens in the member states of the European Union (EU).

Methods-A database called CAREX (carcinogen exposure) was designed to provide selected exposure data and documented estimates of the number of workers exposed to carcinogens by country, carcinogen, and industry. CAREX includes data on agents evaluated by the International Agency for Research on Cancer (IARC) (all agents in groups 1 and $2 A$ as of February 1995, and selected agents in group $2 \mathrm{~B}$ ) and on ionising radiation, displayed across the 55 industrial classes. The 1990-3 occupational exposure was estimated in two phases. Firstly, estimates were generated by the CAREX system on the basis of national labour force data and exposure prevalence estimates from two reference countries (Finland and the United States) which had the most comprehensive data available on exposures to these agents. For selected countries, these estimates were then refined by national experts in view of the perceived exposure patterns in their own countries compared with those of the reference countries.
\end{abstract}

Results-About 32 million workers (23\% of those employed) in the EU were exposed to agents covered by CAREX. At least 22 million workers were exposed to IARC group 1 carcinogens. The exposed workers had altogether 42 million exposures (1.3 mean exposures for each exposed worker). The most common exposures were solar radiation $(9.1 \mathrm{mil}-$ lion workers exposed at least $75 \%$ of working time), environmental tobacco smoke (7.5 million workers exposed at least $75 \%$ of working time), crystalline silica (3.2 million exposed), diesel exhaust (3.0 million), radon ( 2.7 million), and wood dust (2.6 million).

Conclusion-These preliminary estimates indicate that in the early 1990s, a substantial proportion of workers in the EU were exposed to carcinogens.

(Occup Environ Med 2000;57:10-18)

Keywords: exposure; carcinogen; Europe
Effective prevention of occupational cancer requires knowledge on occurrence of exposure but information on the numbers of workers exposed is seldom available. As a part of a European project on the estimation of the burden of occupational cancer in Europe, ${ }^{1}$ an international group of experts was established to provide documented estimates of the number of workers in the European Union (EU) exposed to carcinogens by country, agent, and industry. A first version of an exposure information system called CAREX (carcinogen exposure) was constructed by the Finnish Institute of Occupational Health (FIOH) to support the estimation process. CAREX was further developed by a group of experts, which included additional experts on national exposure from different countries in the EU as part of the CAREX network.

Material and methods

OVERVIEW OF THE METHOD

The assessment procedure is outlined in the figure. The main phases of the assessment were the following: (a) definition of agents and occupational exposure; $(b)$ definition of industries and collection of labour force data; (c) collection of exposure measurement data and descriptive exposure data; (d) generation of default estimates of exposures by the CAREX system on the basis of United States and Finnish exposure data and estimates; (e) earmarking of exposures of low level; $(f)$ estimation of multiple exposures to convert the number of exposures to the number of exposed workers; and ( $g$ ) generation of final estimates of exposures by national experts in selected countries. To support the estimation and to document the basis for estimates, a CAREX exposure information system was designed and constructed. It is an MS Access database which can be run on personal computers.

\section{AGENTS COVERED AND DEFINITION OF}

OCCUPATIONAL EXPOSURE

CAREX covers all agents, groups of agents, and mixtures which the International Agency for Research on Cancer (IARC) had classified to group 1 (carcinogenic to humans) and group 2A (probably carcinogenic to humans) as of February 1995. Selected agents from group 2B (possibly carcinogenic to humans) were also included. In addition, ionising radiation was included, although not yet evaluated by IARC.

Many of the group 1 and 2A agents are polycyclic aromatic hydrocarbons (PAHs) or their mixtures, and they were merged under that 


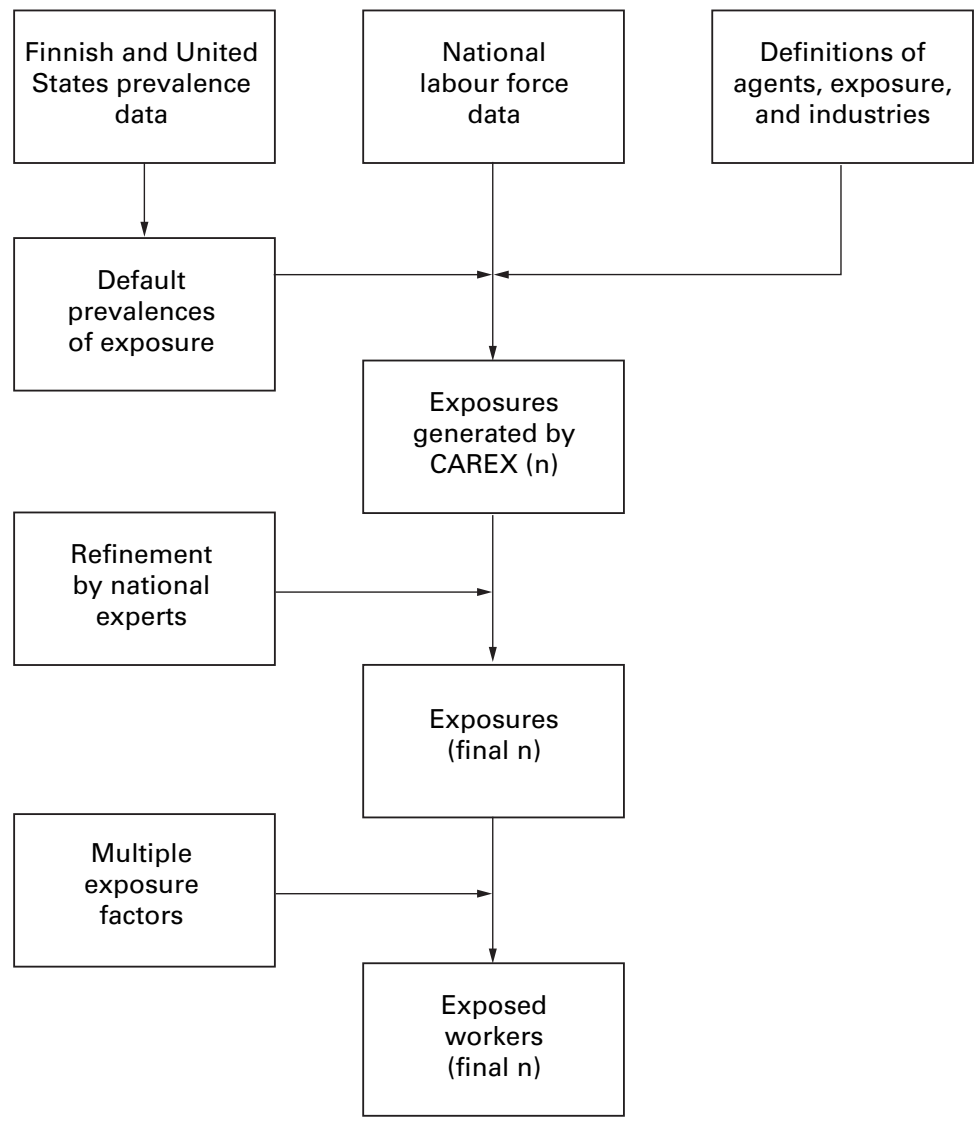

CAREX estimation procedure. See table 1 for details on use of Finnish and United States prevalence data to generate default prevalences. Estimates were refined by national experts in Denmark, France, Italy, and The Netherlands. Also, CAREX includes exposure

measurement data and selected data on exposure by occupation and sex.

title. The PAHs include coal tar pitches, coal tars, untreated and mildly treated mineral oils, shale oils, soots and creosotes, as well as benzo(a)pyrene and other single $\mathrm{PAH}$ compounds. The reason for this regrouping was that PAHs almost always occur in occupational settings as complex mixtures and evaluation of exposures to a single $\mathrm{PAH}$ is not usually possible. However, tobacco smoke (passive exposure at work) and diesel exhaust, although recognised also as complex mixtures containing PAHs, were assessed separately. Ultraviolet radiation $\mathrm{A}, \mathrm{B}$, and $\mathrm{C}$ were merged under the title artificial ultraviolet radiation, which was assessed separately from solar radiation. Exposure to hepatitis viruses $\mathrm{B}$ and $\mathrm{C}$ were not assessed due to difficulties in defining the concept of exposure.

The definition of occupational exposure to an agent in CAREX provided the relevant routes of exposure (inhalatory, dermal, or both of them) and the non-occupational background level, which was used as the minimum criterion of occupational exposure. If a CAREX agent was a group of substances, the definition listed the most common substances included. The definition noted in some cases inclusions or exclusions of borderline exposures-for example, occasional paint removal was not considered to entail exposureand national deviations from the general definition - for example, agent $\mathrm{X}$ in country $\mathrm{Y}$ was considered to entail exposure also when it occurred as an impurity in polymeric materials.

Most agents and groups of agents in CAREX ( $\mathrm{n}=85$ items, including PAHs as one item) were assessed according to a detailed industry specific procedure which provides 55 industry specific estimates for the number of exposed workers per country and agent. The assessment of nine agents, including artificial ultraviolet radiation, erionite, and Helicobacter pylori, followed a country specific procedure which provides only one estimate per country and agent. Carcinogenic exposure circumstances evaluated by IARC ( $\mathrm{n}=15$ items) were only briefly described in CAREX. No assessment was appropriate or feasible for some of the carcinogenic agents ( $\mathrm{n}=8$ items, betel quid, some viruses, salted fish, etc) for which exposure is not primarily occupational. They were included in the database but the number of occupationally exposed workers was assumed to be zero.

\section{CHARACTERISATION OF INDUSTRY AND LABOUR} FORCE

The numbers of exposures and exposed workers in CAREX were estimated mainly for industrial classes (CAREX industries) at the three digit level of United Nations (UN) international standard industrial classification (ISIC) revision 2 (1968). For some nonmanufacturing sectors, one or two digit levels were used as the assessment level. The number of industrial classes in CAREX was 55 .

The number of employed people used in the calculation was the mean number of employed people in 1990-3, because more recent uniform labour force statistics were not available. As far as possible, we tried to include all people employed in each industry by covering salaried workers, self employed workers, working family members, and part time workers. The main source of labour force data was the Organisation for Economic Co-operation and Development (OECD) which has uniformly collected labour force statistics according to the ISIC revision 2 classification since the late 1960s. Available national statistics were also used and whenever needed, national experts corrected and completed the data.

EXPOSURE MEASUREMENTS AND DESCRIPTIONS IN CAREX

A valid estimation of the level of exposure in CAREX would have required that the levelsfor example, high and low-were accurately defined, and that enough knowledge on exposure circumstances from different countries was available. An initial study indicated that a systematic estimation of exposures by level in each of the 15 EU countries was unfeasible during the present project. However, CAREX contains agent and industry specific measurement data to enable users of the database to arrive at their own estimations and conclusions on exposure levels. CAREX also includes some data on carcinogenic exposures by occupation and sex at the national level. 
Table 1 Rational to derive default (first) estimates of exposure from the United States and Finnish exposure prevalences

\begin{tabular}{llll}
\hline & \multicolumn{3}{l}{ Finnish prevalence } \\
\cline { 2 - 4 } & Valid & Invalid & Zero \\
\hline United States prevalence: & & & \\
Valid & AVE & USA & AVE \\
Invalid & FIN & AVE & ZERO \\
Missing & FIN & OWN & ZERO \\
Zero & AVE & ZERO & ZERO \\
\hline
\end{tabular}

$\mathrm{AVE}=$ average prevalence of exposure in Finland and the United States was used; USA=prevalence in the United States was used; FIN=prevalence in Finland was used; OWN=own national estimate was proposed; $\mathrm{ZERO}=$ no exposure was assumed to occur.

\section{DEFAULT ESTIMATES}

Our preference was to use original national estimates on carcinogenic exposures, but their poor availability forced us to adopt an approach in which most estimates were derived indirectly on the basis of information from the two reference countries with reasonably comprehensive data (Finland and the United States).

After conversion of the Finnish and United States industrial classifications to ISIC revision 2 of UN 1968 format, the estimated number of workers exposed to the IARC agents under study were listed by industry. These absolute figures were converted to exposure frequencies (prevalences) by dividing them by the employed labour force of the industry concerned. These prevalences were used to calculate three alternative estimates (AVE, USA, FIN) for exposures in other countries (table 1). The estimate considered to be the most valid by professional judgement was set as the default value. When the estimate was not unanimously considered to be zero, usually the average (AVE) value was used. If the average prevalence was not used, the reason was documented in CAREX. In rare cases in which both United States and Finnish estimates were considered invalid, AVE was used because the United States prevalence was regarded as too high and the Finnish one as too low.

ESTIMATES OF LOW LEVEL

If the level of exposure was considered to be close to the background level (in ambient or indoor air), the estimate was marked as such. However, the background exposure may vary and is often difficult to specify. Many low exposures in Finnish data involved handling of small amounts of carcinogens in laboratories, pharmacies, or hospitals. Low exposures were tagged by professional judgement in Finland. The United States National Occupational Exposure Survey (NOES) did not classify exposures by level and therefore low exposures could not be systematically identified. The Finnish estimates which were judged as low were used as one basis to mark NOES estimates. However, no NOES data were considered as invalid on this basis, which resulted in tagging of some exposures in laboratories as low level in the United States when similar exposures were not considered to entail exposure exceeding the background level in
Finland. Similarly, exposure to many impurities in polymeric materials and metal alloys were considered as low exposure in the United States and as being negligible in Finland. Another criterion to assign a low exposure flag to NOES data was an obvious discrepancy with the Finnish data without an evident reason. For example, if there were over 10000 exposed workers in a CAREX industry in NOES and none in Finland, it was assumed that the United States exposures were of low level. Also, some very small estimates of the number of workers potentially exposed were considered to reflect low exposure in the NOES data.

ESTIMATES OF MULTIPLE EXPOSURE

The concept exposure in CAREX does not refer to the number of exposure events-for example, five times a year-but to the occurrence of agent specific exposures of a worker. For example, if one worker is exposed to two agents, the number of exposed workers is one, but the number of exposures is two. The distinction between exposure and exposed worker is necessary in the calculation of total numbers of exposed workers in a CAREX industry, or in a country. If all exposures within an industry are totalled, the same workers may be counted several times (in cases of multiple exposure) and an overestimate results. Therefore we developed industry specific factors (multipliers), which converted the number of exposures to number of exposed workers. These multiple exposure factors were derived in CAREX for the Finnish data only, and are based on the assessment of additivity of exposed subgroups by one member of the team (TK). The United States NOES data did not allow for the derivation of multiple exposure factors by CAREX industry coding (ISIC revision 2). The Finnish multipliers were used in the present analysis also for other EU countries.

ESTIMATION PROCEDURES BY COUNTRY

Default estimates generated by the CAREX system were used to describe exposure in Austria, Belgium, Germany, Great Britain, Greece, Ireland, Luxembourg, Portugal, Spain, and Sweden. There is a Swedish national report on exposure to carcinogens ${ }^{2}$ but because the definitions and estimation procedures were different from the CAREX system, these Swedish estimates were not incorporated in CAREX.

The estimates of the reference countries were based on direct national data. The Finnish estimates were generated and documented in CAREX as accurately as possible at subindustrial level. The main sources of Finnish data were the reports of a comprehensive estimation survey (SUTKEA project) carried out by industrial hygienists of the Finnish Institute of Occupational Health (FIOH) in the late 1980s and early 1990s. ${ }^{3}$ Another basic source of information was the Finnish national register of workers exposed to carcinogens (ASA register) kept by $\mathrm{FIOH}$ since $1979 .{ }^{4}$ If neither SUTKEA nor ASA provided estimates, other available sources, such as the FINJEM exposure information system of the $\mathrm{FIOH}$, were 
Table 2 Numbers of employed workers, exposures, and exposed workers (in thousands) in the European Union by industry in 1990-3

\begin{tabular}{|c|c|c|c|c|}
\hline ISIC-2 code & Industry & Employed workers ( $n$ ) & Exposures (n) & Exposed workers (n) \\
\hline 11 & Agriculture and hunting & 7900 & 3000 & 3000 \\
\hline 12 & Forestry and logging & 410 & 560 & 350 \\
\hline 13 & Fishing & 230 & 150 & 150 \\
\hline 21 & Coal mining & 370 & 1 & 1 \\
\hline 22 & Crude petroleum and natural gas production & 130 & 43 & 43 \\
\hline 23 & Metal ore mining & 62 & 150 & 29 \\
\hline 29 & Other mining & 270 & 450 & 190 \\
\hline $311-2$ & Food manufacturing & 2700 & 330 & 310 \\
\hline 313 & Beverage industries & 410 & 59 & 59 \\
\hline 314 & Tobacco manufacture & 88 & 4 & 4 \\
\hline 321 & Manufacture of textiles & 1300 & 240 & 220 \\
\hline 322 & Manufacture of wearing apparel & 1500 & 350 & 340 \\
\hline 323 & Manufacture of leather and products of leather & 180 & 41 & 40 \\
\hline 324 & Manufacture of footwear & 460 & 89 & 88 \\
\hline 331 & Manufacture of wood and wood and cork products & 770 & 620 & 500 \\
\hline 332 & Manufacture of furniture and fixtures & 790 & 810 & 600 \\
\hline 341 & Manufacture of paper and paper products & 730 & 170 & 140 \\
\hline 342 & Printing, publishing, and allied industries & 1700 & 450 & 440 \\
\hline 351 & Manufacture of industrial chemicals & 1000 & 460 & 350 \\
\hline 352 & Manufacture of other chemical products & 950 & 380 & 340 \\
\hline 353 & Petroleum refineries & 130 & 85 & 74 \\
\hline 354 & Manufacture of petroleum and coal products & 26 & 18 & 18 \\
\hline 355 & Manufacture of rubber products & 380 & 140 & 140 \\
\hline 356 & Manufacture of plastic products & 840 & 380 & 330 \\
\hline 361 & Manufacture of pottery, china, and earthware & 260 & 250 & 170 \\
\hline 362 & Manufacture of glass and glass products & 300 & 200 & 130 \\
\hline 369 & Manufacture of other non-metallic mineral products & 640 & 530 & 430 \\
\hline 371 & Iron and steel basic industries & 850 & 560 & 380 \\
\hline 372 & Non-ferrous metal basic industries & 360 & 230 & 160 \\
\hline 381 & Manufacture of fabricated metal products & 2800 & 1300 & 810 \\
\hline 382 & Manufacture of machinery except electrical & 3800 & 1200 & 830 \\
\hline 383 & Manufacture of electrical machinery & 3000 & 470 & 440 \\
\hline 384 & Manufacture of transport equipment & 3000 & 1500 & 970 \\
\hline 385 & Manufacture of instruments, etc & 540 & 200 & 190 \\
\hline 39 & Other manufacturing industries & 400 & 120 & 110 \\
\hline 41 & Electricity, gas, and steam & 1200 & 480 & 430 \\
\hline 42 & Water works and supply & 220 & 84 & 84 \\
\hline 5 & Construction & 11000 & 9000 & 6100 \\
\hline 6 & Wholesale and retail trade and restaurants & 24000 & 4200 & 3500 \\
\hline 711 & Land transport & 4200 & 1900 & 1700 \\
\hline 712 & Water transport & 350 & 250 & 180 \\
\hline 713 & Air transport & 450 & 330 & 290 \\
\hline 719 & Services allied to transport & 1400 & 630 & 580 \\
\hline 72 & Communication & 2600 & 610 & 590 \\
\hline 8 & Financing, insurance, real estate, business services & 13000 & 1100 & 1100 \\
\hline 91 & Public administration and defence & 11000 & 1600 & 1600 \\
\hline 92 & Sanitary and similar services & 1400 & 430 & 360 \\
\hline 931 & Education services & 9000 & 370 & 330 \\
\hline 932 & Research and scientific institutes & 490 & 140 & 100 \\
\hline 933 & Medical, dental, other health services & 8200 & 810 & 730 \\
\hline 934 & Welfare institutions & 4000 & 220 & 210 \\
\hline $935-9$ & Business, professional, and other organisations & 1500 & 230 & 230 \\
\hline 94 & Recreational and cultural services & 2100 & 280 & 270 \\
\hline 95 & Personal and household services & 32000 & 3800 & 1600 \\
\hline \multirow[t]{2}{*}{96} & International organisations & 160 & 1 & 1 \\
\hline & Total & 139000 & 42000 & 32000 \\
\hline
\end{tabular}

used. ${ }^{5}$ The basic criterion for assigning exposure in Finland was that the annual exposure dose at work exceeded the non-occupational dose.

The United States was the other reference country in the CAREX system. The United States data in CAREX came from the NOES conducted by the United States National Institute for Occupational Safety and Health $(\mathrm{NIOSH})$. The NOES was a nationwide observational survey conducted in a sample of 4490 establishments from $1981-3 .^{6-9}$ The target population was defined as employees working in establishments or job sites in the United States employing eight or more workers in a defined list of standard industrial classifications. Generally, these classifications emphasised coverage of construction, manufacturing, transportation, private and business service, and hospital industries. The NOES had little or no sampling activity in agriculture, mining, wholesale or retail trades, finance and real estate, or government operations. The NOES considered recordable potential exposure. A potential exposure had to meet two criteria to be recorded: (a) a chemical, physical, or biological agent, or a tradename product had to be found close enough to an employee that one or more physical phases of that agent or product were likely to enter or contact the body of the employee; and (b) the duration of the potential exposure had to meet the minimum duration guidelines (at least 30 minutes a week on an annual average, or at least once a week for $90 \%$ of the weeks of the working year).

Denmark, France, Italy, and the Netherlands produced estimates which are adjusted for the labour force structure and account for exposure patterns in the country. The Danish estimates were based on several nationwide surveys. ${ }^{10-14}$ If no appropriate estimates were available from the Danish surveys, the default estimates of the CAREX system were used, unless they were considered invalid for Denmark on the basis of subjective judgement. 
Table 3 Numbers of exposures by agent (in thousands) in the European Union in 1990-3

\begin{tabular}{|c|c|c|}
\hline Agent & Exposures (n) & IARC group ${ }^{\star}$ \\
\hline Acrylamide & 31 & $2 \mathrm{~A}$ \\
\hline Acrylonitrile & 32 & $2 \mathrm{~A} \dagger$ \\
\hline Adriamycin & 18 & $2 \mathrm{~A}$ \\
\hline Aflatoxins & 2 & 1 \\
\hline 4-Aminobiphenyl & 0 & 1 \\
\hline Arsenic and arsenic compounds & 150 & 1 \\
\hline Asbestos & 1200 & 1 \\
\hline Azacitidine & 1 & $2 \mathrm{~A}$ \\
\hline Azathioprine & 2 & 1 \\
\hline Benzene & 1400 & 1 \\
\hline Benzidine & 7 & 1 \\
\hline Benzidine based dyes & 14 & $2 \mathrm{~A}$ \\
\hline Beryllium and beryllium compounds & 67 & 1 \\
\hline Bischloroethyl nitrosourea (BCNU) & 10 & $2 \mathrm{~A}$ \\
\hline Bis(chloromethyl)ether (BCME) & 2 & 1 \\
\hline 1,3-Butadiene & 32 & $2 \mathrm{~A}$ \\
\hline 1,4-Butanediol dimethanesulphonate (Myleran) & 3 & 1 \\
\hline Cadmium and cadmium compounds & 210 & 1 \\
\hline Captafol & 8 & $2 \mathrm{~A}$ \\
\hline Carbon tetrachloride & 75 & 2B \\
\hline Ceramic fibres & 62 & $2 \mathrm{~B}$ \\
\hline Chlorambucil & 10 & 1 \\
\hline Chloramphenicol & 12 & $2 \mathrm{~A}$ \\
\hline 1-(2-Chloroethyl)-3-cyclohexyl-1-nitrosourea (CCNU) & 2 & $2 \mathrm{~A}$ \\
\hline Chlorozotocin & $<1$ & $2 \mathrm{~A}$ \\
\hline Chromium VI compounds & 800 & 1 \\
\hline Cyclosporin & 10 & 1 \\
\hline Cisplatin & 25 & $2 \mathrm{~A}$ \\
\hline Cobalt and its compounds & 240 & $2 \mathrm{~B}$ \\
\hline Cyclophosphamide & 45 & 1 \\
\hline Diesel engine exhaust & 3000 & $2 \mathrm{~A}$ \\
\hline Diethylstilbestrol & $<1$ & 1 \\
\hline Diethyl sulphate & 2 & $2 \mathrm{~A}$ \\
\hline Dimethylcarbamoyl chloride & 0 & $2 \mathrm{~A}$ \\
\hline Dimethyl sulphate & 10 & $2 \mathrm{~A}$ \\
\hline Epichlorohydrin & 48 & $2 \mathrm{~A}$ \\
\hline Estrogens, non-steroidal & 5 & 1 \\
\hline Estrogens, steroidal & 5 & 1 \\
\hline Ethylene dibromide & 1200 & $2 \mathrm{~A}$ \\
\hline Ethylene oxide & 47 & 1 \\
\hline N-Ethyl-N-nitrosourea & 0 & $2 \mathrm{~A}$ \\
\hline Formaldehyde & 990 & $2 \mathrm{~A}$ \\
\hline Glasswool & 930 & $2 \mathrm{~B}$ \\
\hline Hepatitis B virus (HBV) & Not estimated & 1 \\
\hline Hepatitis $\mathrm{C}$ virus (HCV) & Not estimated & 1 \\
\hline Ionising radiation & 150 & - \\
\hline Lead and inorganic lead compounds & 1500 & $2 \mathrm{~B}$ \\
\hline Melphalan & 10 & 1 \\
\hline Methyl-CCNU & $<1$ & 1 \\
\hline N-Methyl-N-nitrosourea & 0 & $2 \mathrm{~A}$ \\
\hline 4,4'-Methylene bis(2-chloroaniline) (MOCA) & 3 & $2 \mathrm{~A}$ \\
\hline Methylene chloride & 280 & $2 \mathrm{~B}$ \\
\hline MNNG & 1 & $2 \mathrm{~A}$ \\
\hline Mustard gas (sulphur mustard) & 1 & 1 \\
\hline 2-Naphthylamine & 2 & 1 \\
\hline Nickel compounds & 560 & 1 \\
\hline Nitrogen mustard & 3 & $2 \mathrm{~A}$ \\
\hline N-Nitrosodiethylamine & 13 & $2 \mathrm{~A}$ \\
\hline N-Nitrosodimethylamine & 14 & $2 \mathrm{~A}$ \\
\hline Oral contraceptives, combined & 5 & 1 \\
\hline Oral contraceptives, sequential & 5 & 1 \\
\hline p-Chloro-o-toluidine and its strong acid salts & 1 & $2 \mathrm{~A}$ \\
\hline Pentachlorophenol & 49 & $2 \mathrm{~B}$ \\
\hline Phenacetin & 3 & $2 \mathrm{~A}$ \\
\hline Polychlorinated biphenyls (PCB) & 15 & $2 \mathrm{~A}$ \\
\hline Polycyclic aromatic hydrocarbons (PAH) & 980 & $1-3$ \\
\hline Procarbazide hydrochloride & $<1$ & $2 \mathrm{~A}$ \\
\hline Radon and its decay products & 2700 & 1 \\
\hline Silica, crystalline & 3200 & $2 \mathrm{~A} \ddagger$ \\
\hline Solar radiation (at least $75 \%$ of working time) & 9100 & 1 \\
\hline Styrene & 400 & $2 \mathrm{~B}$ \\
\hline Styrene-7,8-oxide & 86 & $2 \mathrm{~A}$ \\
\hline Sulphuric acid mist & 710 & 1 \\
\hline Talc containing asbestiform fibres & 28 & 1 \\
\hline Tetrachloroethylene & 820 & $2 \mathrm{~A}$ \\
\hline Thiotepa & 3 & 1 \\
\hline Tobacco smoke, environmental (at least $75 \%$ of working time) & 7500 & 1 \\
\hline Treosulfan & 0 & 1 \\
\hline Trichloroethylene & 280 & $2 \mathrm{~A}$ \\
\hline 1,2,3-Trichloropropane & 1 & $2 \mathrm{~A}$ \\
\hline Tris(2,3-dibromopropyl)phosphate & $<1$ & $2 \mathrm{~A}$ \\
\hline Vinyl bromide & 0 & $2 \mathrm{~A}$ \\
\hline Vinyl chloride & 40 & 1 \\
\hline Vinyl fluoride & 0 & $2 \mathrm{~A}$ \\
\hline Wood dust & 2600 & 1 \\
\hline Total & 42000 & \\
\hline
\end{tabular}

${ }^{\star}$ IARC groups: $1=$ carcinogenic to humans; $2 \mathrm{~A}=$ probably carcinogenic to humans; $2 \mathrm{~B}=$ possibly carcinogenic to humans; $3=$ unclassifiable as to carcinogenicity to humans.

†Re-evaluation 1999 (group 2B). $\quad \ddagger$ Re-evaluation of occupational exposure 1997 (group 1).
The French estimates were based on the observational SUMER survey ${ }^{15}$ conducted in 1994, and the COLCHIC database of occupational exposure measurements maintained by the National Institute of Research on Safety (INRS). If no data were available from the SUMER study, the estimates were based on knowledge of different INRS experts, or on default estimates of CAREX. All temporary workers independently of the employing sector in France were coded to ISIC "wholesale and retail trade and restaurants and hotels" resulting in occurrence of unexpected exposures in that class.

The Italian estimates were generated by CAREX system and modified by a national expert who based his judgements either on his own experience or on the evaluations received from a group of Italian industrial hygienists. These industrial hygienists had developed an industrial activity or exposure matrix within the framework of an occupational hazards surveillance programme in 1996-7 in the Piedmont region.

The Dutch estimates were generated by the CAREX system and modified by a national expert who used several inputs. These included the WAUNC database of the Wageningen University, containing approximately 20000 chemical exposure measurements as a data source. Input from colleagues was used to some extent. Also, unpublished data from the Ministry of Social Affairs and Employment on the occurrence of exposure to carcinogens by industry and process was taken into account.

\section{Results}

There were about 32 million workers $(23 \%$ of the total employed) in the 15 countries of the EU exposed to the agents covered by CAREX in 1990-3 (table 2). These workers had altogether 42 million exposures (1.3 exposures for each exposed worker on average). Exposure to carcinogenic agents or factors was widespread in many industrial classes included in CAREX. Industries where exposures were most prevalent include forestry (solar radiation), fishing (solar radiation), other mining (silica, diesel exhaust), wood and furniture industries (wood dust, formaldehyde), manufacture of mineral products (silica), construction (silica, solar radiation, diesel exhaust), and air transport (environmental tobacco smoke, ionising radiation).

The total numbers of exposed workers by agent are presented in table 3. The most common exposures in the EU countries were solar radiation (9.1 million workers exposed at least $75 \%$ of working time), environmental tobacco smoke (7.5 million workers exposed at least $75 \%$ of working time), crystalline silica (3.2 million exposed), diesel exhaust (3.0 million), radon (2.7 million), wood dust (2.6 million), lead and inorganic lead compounds (1.5 million), and benzene ( 1.4 million). For seven agents (4-aminobiphenyl, dimethylcarbamoyl chloride, N-ethyl-N-nitrosourea, N-methyl-Nnitrosourea, treosulfan, vinylbromide, and vinylfluoride) no occupational exposure was identified as having occured in the EU. 
Table 4 The most common carcinogen exposures (in thousands) by country in 1990-3

\begin{tabular}{|c|c|c|c|c|c|c|c|c|c|c|c|c|c|c|c|}
\hline Agent & $A$ & $B$ & $D$ & $D K$ & $E$ & $F$ & FIN & $G B$ & $G R$ & $I$ & $I R L$ & $L$ & $N L$ & $P$ & $S$ \\
\hline Solar radiation & 240 & 200 & 2400 & 180 & 1100 & 1500 & 180 & 1300 & 460 & 560 & 110 & 14 & 290 & 370 & 240 \\
\hline Tobacco smoke, environmental & 180 & 190 & 2000 & 100 & 670 & 1200 & 110 & 1300 & 170 & 770 & 58 & 11 & 350 & 210 & 210 \\
\hline Silica, crystalline & 100 & 74 & 1000 & 59 & 400 & 110 & 83 & 590 & 87 & 280 & 29 & 7 & 170 & 83 & 86 \\
\hline Diesel exhaust & 79 & 67 & 720 & 71 & 270 & 410 & 39 & 470 & 79 & 550 & 21 & 4 & 110 & 73 & 81 \\
\hline Radon & 72 & 86 & 820 & 0 & 280 & 520 & 49 & 560 & 66 & 38 & 24 & 4 & 0 & 92 & 99 \\
\hline Wood dust & 82 & 55 & 680 & 51 & 400 & 180 & 65 & 430 & 51 & 320 & 18 & 4 & 95 & 86 & 84 \\
\hline Lead and its compounds & 37 & 30 & 460 & 23 & 100 & 140 & 13 & 250 & 24 & 290 & 9 & 3 & 49 & 33 & 35 \\
\hline Benzene & 49 & 21 & 470 & 49 & 90 & 70 & 14 & 300 & 35 & 190 & 11 & 2 & 43 & 43 & 34 \\
\hline Asbestos & 15 & 10 & 160 & 9 & 57 & 140 & 7 & 95 & 15 & 680 & 6 & 1 & 14 & 16 & 12 \\
\hline Ethylene dibromide & 46 & 17 & 440 & 27 & 81 & 10 & 12 & 280 & 33 & 170 & 10 & 2 & 19 & 40 & 31 \\
\hline Formaldehyde & 17 & 16 & 130 & 90 & 71 & 310 & 11 & 94 & 10 & 180 & 3 & 0.6 & 16 & 36 & 11 \\
\hline PAH & 19 & 17 & 210 & 13 & 55 & 120 & 6 & 110 & 13 & 350 & 4 & 2 & 26 & 21 & 18 \\
\hline Glasswool & 23 & 19 & 250 & 14 & 92 & 130 & 12 & 140 & 17 & 150 & 6 & 2 & 34 & 19 & 20 \\
\hline Tetrachloroethylene & 19 & 12 & 210 & 11 & 47 & 140 & 3 & 120 & 14 & 180 & 5 & 1 & 21 & 21 & 16 \\
\hline Chromium (VI) compounds & 18 & 19 & 260 & 25 & 57 & 70 & 10 & 130 & 10 & 130 & 5 & 1 & 29 & 21 & 21 \\
\hline Sulphuric acid mist & 7 & 10 & 100 & 4 & 20 & 380 & 2 & 42 & 3 & 120 & 2 & 1 & 10 & 5 & 8 \\
\hline Nickel compounds & 12 & 15 & 200 & 11 & 43 & 50 & 8 & 85 & 6 & 79 & 3 & 1 & 19 & 12 & 17 \\
\hline Styrene & 6 & 10 & 110 & 36 & 28 & 50 & 3 & 54 & 4 & 66 & 2 & 0.5 & 12 & 7 & 9 \\
\hline Methylene chloride & 2 & 3 & 29 & 23 & 7 & 60 & 1 & 15 & 1 & 130 & 1 & 0.2 & 3 & 3 & 2 \\
\hline Trichloroethylene & 2 & 2 & 33 & 7 & 6 & 110 & 1 & 16 & 1 & 90 & 1 & 0.1 & 3 & 2 & 2 \\
\hline Total, exposures & 1100 & 910 & 11100 & 880 & 4000 & 6000 & 650 & 6600 & 1100 & 5600 & 330 & 63 & 1400 & 1200 & 1100 \\
\hline Total, exposed workers & 790 & 730 & 8300 & 680 & 3100 & 4900 & 510 & 5000 & 910 & 4200 & 260 & 48 & 1100 & 970 & 820 \\
\hline Exposed/employed (\%) & 25 & 21 & 24 & 24 & 25 & 23 & 24 & 22 & 27 & 24 & 24 & 25 & 17 & 24 & 20 \\
\hline
\end{tabular}

A=Austria; B=Belgium; D=Germany; DK=Denmark; E=Spain; F=France; FIN=Finland; GB=Great Britain; GR=Greece; I=Italy; IRL=Ireland; L=Luxembourg; $\mathrm{NL}=$ The Netherlands; $\mathrm{P}=$ Portugal; $\mathrm{S}=$ Sweden.

Exposure to hepatitis viruses B and C may occur in the treatment of blood but the numbers of exposed workers could not be estimated.

An estimated 22-24 million workers were exposed to group 1 IARC carcinogens. The most common exposures among group 1 agents were to solar radiation, environmental tobacco smoke, crystalline silica, radon, and wood dust.

These figures are conditional to the minimum criteria of exposure. If low level exposures (close to the non-occupational background) are excluded, the numbers of exposed workers would be $15 \%-20 \%$ lower. On the other hand, the figures for solar radiation and environmental tobacco smoke would have been still higher if short term exposure had been included. The estimate for the number of workers exposed to radon was high. The source of radon exposure is the ground which in certain regions emits radioactive radon gas exposing mainly employees working regularly in ground floors of buildings. The high number of workers considered still to be exposed to benzene was predominantly due to car repair where dermal contact with gasoline containing benzene may occur.

The numbers of exposed workers by country (table 4) ranged from about 50000 in Luxembourg to over 8 million in Germany. The proportion of exposed workers from the employed labour force varied between $17 \%$ in the Netherlands and $27 \%$ in Greece. Solar radiation was a very prevalent exposure in countries such as Greece, Portugal, Spain, and Ireland, where agriculture and fishing are the main industries. Passive smoking at work was estimated to be the most common exposure in Great Britain, the Netherlands, and Italy. Relatively high prevalence of exposure to silica and radon were typical of Finland. Formaldehyde was reported to be a common air contaminant in Denmark and France. Asbestos, diesel exhaust, and PAHs were prevalent exposures in Italy. However, these comparisons between countries should be considered with caution because the country specific exposure patterns were not taken into account in all countries, and there were probably also differences between countries in the inclusion of low and potential exposures.

\section{Discussion}

The strengths of the CAREX system are its systematic nature, wide coverage, and ease of use. CAREX tries to apply basically the same definitions and procedures to each country, which tends to improve the comparability and consistency of results across countries. It covers all industries in an international classification of industries and is able to provide both national and industry specific estimates. Major known and suspected carcinogens found in the occupational environment, as evaluated by IARC, are included. CAREX is easy to use in personal computers and can be used to produce a large selection of reports. It can be applied to new (non-EU) countries to generate preliminary estimates of numbers of exposed workers, provided that reasonably accurate statistics on the national labour force are available.

The validity of the CAREX estimates was extensively discussed in the planning team before the construction of CAREX, and several measures to improve validity were adopted. Firstly, all estimates were standardised by the labour force structure of individual countries. Secondly, uniform definitions of agents and of occupational exposure, with inclusions and exclusions, were used to improve consistency. Thirdly, preliminary estimates were in some countries checked and modified by national experts familiar with the exposure situation in their own country. Fourthly, exposures in the reference countries were documented and estimated as specifically (at the subindustrial level) as possible to provide a sufficient knowledge base for the estimations in other countries. Fifthly, industrial hygiene data and descriptive information of exposures were included in the 
database to support estimation efforts. Sixthly, estimates suspected to represent low levels of occupational exposure were marked to allow their inclusion or exclusion since low exposures may have a strong effect on the estimated numbers of exposed. Seventhly, preliminary estimates for non-reference countries were selected by professional judgement to be the most valid out of alternative estimates AVE, FIN, United States, OWN, or ZERO. Despite of these precautions and the aids included in the CAREX system, there are still many validity issues of concern-such as differences of country specific use patterns for carcinogens, differences of national survey protocols, time frame, national industrial coding systems (conversion difficulties), and assessment of multiple exposures. These points are discussed separately below.

Omission of country specific exposure patterns may bias results seriously. One illustrative example is exposure to radon from the ground which is higher in Finland than in most EU countries possibly resulting in overestimation in other countries if not adequately checked by national experts. Similar potential for bias concerns crystalline silica, because Finnish stone and construction materials often contain granite and thereby silica. Solar radiation has the opposite potential for bias. Direct use of Finnish prevalence figures (prevalence of regular outdoor workers) is likely to result in underestimation for countries in southern Europe where many part time outdoor workers will be occupationally exposed to higher doses than regular outdoor workers in Finland due to more intense solar radiation. The industrial substructure of many countries may also differ considerably from the United States and Finland depending on the type of products or processes used. This may be true particularly for the chemical industries.

Different legislation may lead to large variations in exposure patterns between countries, as is the case of asbestos or passive smoking at work. Sometimes the use pattern is strongly influenced by national price policy. For example, exposure to ethylene dibromide (scavenger agent in leaded gasoline) decreased drastically in Finland in 1990-3 when unleaded gasoline was substituted for more expensive leaded gasoline.

Because the average prevalence of the United States and Finland was preferred in the CAREX procedure, the preliminary estimates inherently assume that the exposure pattern of the country is typically between that of a large country - such as the United States - and that of a smaller country-such as Finland. This assumption may be fairly valid for large European countries (such as the United Kingdom, France, Germany, Italy, and Spain) where a wide range of processes and exposures occur. However, the CAREX procedure probably provides incorrect non-zero estimates for rare exposures which do not occur in small countries with less varying economic structure - such as Luxembourg.

The adjustment of default estimates to correspond with the national situation turned out to be problematic. The national adjustment resulted in an increase of the total number of workers exposed to CAREX agents in Denmark $(+15 \%)$ and France $(+4 \%)$, but a decrease in Italy $(-7 \%)$ and the Netherlands $(-17 \%)$. The impact of the adjustment was also agent specific, extending from nil to substantial-for example, radon. Although national experts were able to adjust figures to correspond better to exposure patterns of their countries, it is likely that the adjustments were sensitive to the definition of exposure-for example, inclusion or exclusion of potential and low exposures - in survey data and other exposure information used by the experts.

The concept of exposure in the reference countries differed. The Finnish protocol required in most cases that non-occupational exposure, measured as annual dose, had to be exceeded, whereas the United States protocol considered potential exposure. The Finnish approach sets the minimum exposure generally at a higher level than the United States approach, and results therefore in lower proportions of exposed workers. The CAREX system compromises between these two concepts by usually applying the average of the United States and Finnish prevalences to calculate preliminary estimates for other countries. This means that the concept of exposure in CAREX is somewhere between potential exposure (as in the United States) and exposure exceeding non-occupational background (as in Finland). CAREX therefore includes some exposures which may be lower than the background. If exposures marked as low (close to the non-occupational background) are excluded, the total number of exposures drops by $3 \%$ in Finland and by $31 \%$ in the United States. For other countries, whose estimates are mainly based on average exposure prevalences occurring in Finland and the United States, the share of low exposures would be on this basis $15 \%-20 \%$.

The United States data were based on an observational field survey and the Finnish data on professional judgement. Both methods have their advantages and disadvantages. The NOES survey was sensitive in identifying exposures whereas the Finnish procedure often neglected small exposed groups and atypical exposures. However, sometimes the opposite was the case. For example, the NOES sample did not include any nickel refineries and was therefore unable to identify nickel exposure in ISIC 372 (manufacture of other metals). The Finnish professional judgement identified nickel refineries and provided a more reliable estimate in this case.

The reference data from the United States came from a field survey performed in 1981-3. Exposure patterns have probably changed after that in the United States and elsewhere. For example, the production or use of some agents - for example, asbestos-has been restricted since then. Although CAREX did not use clearly outdated United States figures as default values, all of them could probably not be identified. Therefore some of the resulting CAREX estimates may follow too closely the 
United States exposure situation in the early 1980s when occupational exposure to some carcinogens probably happened more often than in 1990-3. The Finnish estimates were for the assessment period 1990-3.

Conversions between different industrial coding systems were used in the processing of labour force statistics and United States (NOES) exposure data. The main part of labour force statistics came from OECD directly in the UN ISIC revision 2 coding system. However, the OECD data were not coded originally according to UN ISIC but according to national classifications which are then converted to UN ISIC. In the conversions, different definitions of the employed populations and estimations of missing values caused some inaccuracy and incomparability to the labour force statistics used in CAREX. The United States labour force figures and exposure data were converted from United States standard industrial classification (SIC) (1987 version) through UN ISIC revision 3 to UN ISIC revision 2 . The conversion was carried out at the maximal level of specificity to minimise conversion errors. Despite conversion problems, the order of magnitude of the labour force figures in the reference countries is probably correct and not a main source of error.

The CAREX system applied Finnish values to other EU countries in estimating the degree of multiple exposure. This sometimes resulted in estimates of exposed workers which exceeded even the total labour force of industrial classification. In those cases, the Finnish multiplier clearly underestimated multiple exposure in that country and was inappropriate. National modifications of multiple exposure multipliers are therefore necessary, especially if the exposure pattern is likely to differ significantly from the Finnish one.

The numbers of workers exposed to known or suspected carcinogens generated by the CAREX system and the network of national experts are the first estimates published for the $\mathrm{EU}$ and some of the member countries. In that respect this new approach turned out to be feasible and successful. The results suggest that the number of workers exposed to carcinogenic substances and factors in 1990-3 amounted to about 32 million workers, or about $23 \%$ of the total number of workers employed in the EU. Of these at least 22 million were exposed to agents classified as definite human carcinogens by the IARC. Substantial parts of all exposures originated from natural sources (ultraviolet radiation from the sun, radon from the ground) or from activities not related to work as such (environmental tobacco smoke at work). The contribution of these environmental factors was almost half out of 42 million exposures. The level of exposure for many exposed groups was low, and consequently also the risk of cancer for such groups is likely to be low. If worker groups identified as being exposed to low levels close to the levels originating from ambient and indoor air were to be excluded, the numbers of exposed workers would drop by $15 \%-20 \%$.

Empirical validity testing of CAREX would require well defined and comprehensive field surveys and measurements because validity may vary by agent, industry, and country. Such surveys are laborious and expensive to carry out. We think that the CAREX procedure, especially when supplemented by the assessments of national experts, has produced relatively valid estimates. However, the continuation of this work is recommended for several reasons. Firstly, some of the estimates reported are already outdated. Exposure in many countries has been recently restricted for some agents including asbestos and passive smoking at work. Also leaded gasoline (including ethylene dibromide) has been replaced in some countries largely by unleaded gasoline (including MTBE). Secondly, national exposure patterns were not taken into account in all countries. For example, new data on national radon concentrations would help to improve estimates on occupational radon exposure. Thirdly, the estimates of the reference countries could be critically reviewed against industrial hygiene measurement data which may lead to exclusions of some exposures in CAREX. By contrast, some exposures may have to be added to CAREX. For example, exposure to silica in potato farming (machine sorting of potatoes grown in sandy ground) was not considered to entail exposure elsewhere than in The Netherlands. Industrial hygiene data could be surveyed to find out if exposures like this should be recognised also in other countries. The assessment team could learn from each other's data, which would probably increase awareness of unidentified exposures and risks at a national level. The continuation of work would increase the validity of national estimates and would thereby facilitate quantitative risk assessment, priority setting, and effective prevention of occupational cancer at the European and national levels.

A substantial part of the CAREX data are freely available on the internet through the Finnish Institute of Occupational Health (http://www.occuphealth.fi/list/data/CAREX), or through the IARC (http://www.iarc.fr). The Spanish version of CAREX is under preparation at Institut Municipal d'Investigació Mèdica in Barcelona (http://www.imim.es).

This project was partly financed by the EC-DGV from the Europe against cancer programme (Contract SOC 96-200742 05F02).

1 Kogevinas M, Kauppinen T, Boffetta P, et al. Estimation of the burden of occupational cancer in Europe. Final report. Barcelona: Institut Municipal d'Investigació Mèdica, March 1998 .

2 Lundberg I, Plato N, Nise G. Yrken och cancer. In: Järvholm B, ed. Arbetsliv och hälsa-en kartläggning. (Working life and health - a survey). Solna, Sweden: Arbetslivsinstitutet, 1995:59-66.

3 Anttila A, Jaakkola J, Tossavainen A, et al. Occupational exposure to chemical agents in Finland (in Finnish). Helsinki: Finnish Institute of Occupational Health, 1992. (Exposure at work 34.)

4 Kauppinen T, Savela A, Vuorela R. ASA 1990: employees exposed to carcinogens in Finland in 1990, reviews 18. Helsinki: Finnish Institute of Occupational Health, 1992.

5 Kauppinen T, Toikkanen J, Pukkala E. From cross tabulations to multipurpose exposure information systems: a new job exposure matrix. Am f Ind Med 1998;33:409-17.

6 Greife A, Young R, Carroll M, et al. National Institute for Occupational Safety and Health general industry occupational exposure databases: their structure, capabilities,

7 Seta J, Sundin D, Pedersen D. National occupational exposure survey. Vol I. Survey manual. Cincinnati, Ohio: US Depart-
sure 
ment of Health and Human Services, National Institute for Occupational Safety and Health 1988. (Publication No 88-106.)

8 Sieber W. National occupational exposure survey. Vol II Sampling methodology. Cincinnati, Ohio: US Department of Health and Human Services, National Institute for Occupational Safety and Health, 1990. (Publ No 89-102.)

9 Pedersen D, Sieber W. National occupational exposure survey. Vol III. Analysis of management interview responses. Cincinnati, Ohio: US Department of Health and Human Services, National Institute for Occupational Safety and Health 1990. (Publ No 89-103.)

10 Hansen J. Industriel anvendelse af utvalgde kemiske stoffer og risiko for kraeft, 1979-84. Delrapport II. Udarbejdelse af en eksponeringsmatrice. (Industrial use of selected chemical agents and rish of cancer 1979-84. Report II Construction of an axpons and risk of car . Kober 116.
11 Bjersing M, Hansen J, Schöller C, et al. Kraeftfremkaldende stoffer $i$ Danmark. Forekomst, anvendelse og regulering af 240 Ocarrence, use and regulation of 240 agents) 1989. Kobenhavn. Arbejdsmiljoin-

12 Seedorf L, Olsen E. Exposure to organic solvents I. A survey on the use of solvents. Ann Occup Hyg 1990;34:371-8.

3 Borglum B, Damgaard K, Nielsen S. Trae og mobelindustrien. Tvaersnitsundersogelse: Kemiske stoffer og materialer. (Wood and furniture industry. Cross sectional study: chemical agents and materials). Kobenhavn: At-rapport, 1989:1-31.

14 Brandorf NP, Flyvholm MA, Beck ID, et al. National survey on the use of chemicals in the working environment: estimated exposure events. Occup Environ Med 1995;52: 454-63.

15 Heran Le Roy O, Sandret N. Enquête nationale SUMER 94, premiers résultats (National SUMER 94 survey, preliminary results). Paris: Ministère du Travail et des Affaires Sociales, 1996.

\section{Vancouver style}

All manuscripts submitted to Occup Environ Med should conform to the uniform requirements for manuscripts submitted to biomedical journals (known as the Vancouver style.)

Occup Environ Med, together with many other international biomedical journals, has agreed to accept articles prepared in accordance with the Vancouver style. The style (described in full in the $\mathscr{f} A M A[1]$ ) is intended to standardise requirements for authors, and is the same as in this issue.

References should be numbered consecutively in the order in which they are first mentioned in the text by Arabic numerals on the line in square brackets on each occasion the reference is cited (Manson[1] confirmed other reports[2][3][4][5]). In future references to papers submitted to Occup Environ Med should include: the names of all authors if there are three or less or, if there are more, the first three followed by et al; the title of journal articles or book chapters; the titles of journals abbreviated according to the style of Index Medicus; and the first and final page numbers of the article or chapter. Titles not in Index Medicus should be given in full.

Examples of common forms of references are:

1 International Committee of Medical Journal Editors. Uniform requirements for manuscripts submitted to biomed journals. fAMA 1993;269:2282-6.

2 Soter NA, Wasserman SI, Austen KF. Cold urticaria: release into the circulation of histmaine and eosinophil chemotactic factor of anaphylaxis during cold challenge. N Engl F Med 1976;294:687-90.

3 Weinstein L, Swartz MN. Pathogenic properties of invading micro-organisms. In: Sodeman WA Jr, Sodeman WA, eds. Pathologic physiology, mechanisms of disease. Philadelphia: W B Saunders, 1974:457-72. 